\title{
Cytochromes P-450 and model systems: great diversity of catalyzed reactions
}

\author{
D. MANSUY \\ Laboratoire de Chimie et Biochimie Pharmacologiques et Toxicologiques, URA 400 CNRS, \\ Université René Descartes, 45 rue des Saints-Pères, 75270 Paris Cédex 06, France.
}

\begin{abstract}
The most frequently encountered function of cytochromes P450, the monooxygenation of substrates, is now well understood and depends on the involvement of a high-valent iron-oxo intermediate. The corresponding reactions have been reproduced by using metalloporphyrin model systems, the most efficient catalysts being $\mathrm{Fe}$ (III) or Mn(III) tetraarylporphyrins bearing electronwithdrawing substituents at the $\beta$-pyrrole positions. More recently, cytochromes P450 were found able to catalyze very different reactions like isomerisations, reductions and dehydrations . Moreover, nitric oxide synthases are P450-like hemeproteins which contain a heme binding sequence very similar to that of cytochromes P450. These NO synthases could be the most sophisticated members of the P450 superfamily.
\end{abstract}

\section{A. INTRODUCTION}

Since their discovery around 1960, cytochromes P450 have been found to be ubiquitous hemeproteins in living organisms. Until recently, their catalytic function appeared to be the transfer of one oxygen atom from $\mathrm{O}_{2}$ into various substrates. For this monooxygenase reaction (eq.1) cytochromes $\mathrm{P} 450$ receive electrons coming from NADPH or NADH via electron transfer proteins always including a flavoprotein called cytochrome $\mathrm{P} 450$ reductase. More than 200 cytochromes P450 have been cloned and sequenced so far (1).

$$
\mathrm{RH}+\mathrm{O}_{2}+2 \mathrm{e}^{-}+2 \mathrm{H}^{+} \rightarrow \mathrm{ROH}+\mathrm{H}_{2} \mathrm{O}
$$

They all contain $\mathrm{Fe}(\mathrm{III})$ protoporphyrin $\mathrm{XX}$ as a cofactor which is bound to the apoprotein by a cysteinate$\mathrm{Fe}$ (III) bond, and their $\mathrm{Fe}$ (II) complex with $\mathrm{CO}$ exhibits a characteristic Soret peak around $450 \mathrm{~nm}$ (2). Cytochrome P450-dependent monooxygenases play two main roles in living organisms. A class of cytochromes P450 catalyze oxidation steps involved in the biosynthesis and biodegradation of endogenous compounds like steroids or fatty acids. Another class of cytochromes P450 play a central role in the oxidative metabolism and elimination of xenobiotics. Those enzymes are thus very important for the adaptation of living organisms to their environment. The use of model iron porphyrins was very important for the detailed determination of the catalytic cycle of cytochromes P450 acting in monooxygenases. Simultaneous studies performed on cytochromes P450 and on iron porphyrin models in the 1970-1980 period have not only led to a good understanding of the cytochrome P450 catalytic cycle but also to a detailed mechanism of the oxidations of its various substrates (2-4). They have also shown the existence of an exceptionally rich coordination chemistry of these hemeproteins $(4,5)$.

Then, during the 1980-1990 period, very efficient chemical model systems, able to reproduce the catalytic functions of cytochrome P450-dependent monooxygenases, have been obtained (3-9). Some very recent developments concerning these chemical models will be described in the following.

Very recently, during these last few years or months, new catalytic functions of cytochromes P450, different from oxygen atom transfers, have been reported. Some of these new cytochrome P450 reactions will be indicated in the last chapter. This surprising diversity of reactions catalyzed by cytochromes $\mathrm{P} 450$ will be interpreted by considering the various intermediates of the catalytic cycle of cytochrome P450dependent monooxygenases. 


\section{B. CATALYTIC CYCLE OF CYTOCHROME P450-DEPENDENT MONOOXYGENASES.}

Fig. 1 shows a schematic view of this catalytic cycle, with the successive involvement of $\mathrm{P} 450 \mathrm{Fe}$ (III), the resting state of the hemeprotein, $\mathrm{P} 450 \mathrm{Fe}$ (II) and $\mathrm{P} 450 \mathrm{Fe}(\mathrm{II})-\mathrm{O}_{2}$, which have been all very well characterized, and the active oxygen complex of the $\mathrm{Fe}(\mathrm{V})=\mathrm{O}$ type, which has never been observed because of its very short life-time. The oxoferryl nature of this active species is suggested from many data coming from mechanistic studies of $\mathrm{P} 450$ reactions with various substrates and from a comparison with analogous $\mathrm{Fe}=\mathrm{O}$ complexes obtained with iron porphyrin models and with other hemeproteins like peroxidases.

$$
\mathrm{RH}+\mathrm{AO} \stackrel{\mathrm{P} 450}{\longrightarrow} \mathrm{ROH}+\mathrm{AO} \quad \text { (eq.2) }
$$

In that regard, the ability of cytochrome $\mathrm{P} 450$ to catalyze the monooxygenation of substrates either by $\mathrm{NADPH}$ and $\mathrm{O}_{2}$ or by simple oxygen atom donors (eq.2) (shortened catalytic cycle of Fig.1) was also a crucial argument in favor of a $\mathrm{Fe}=\mathrm{O}$ structure for the active oxygen complex.

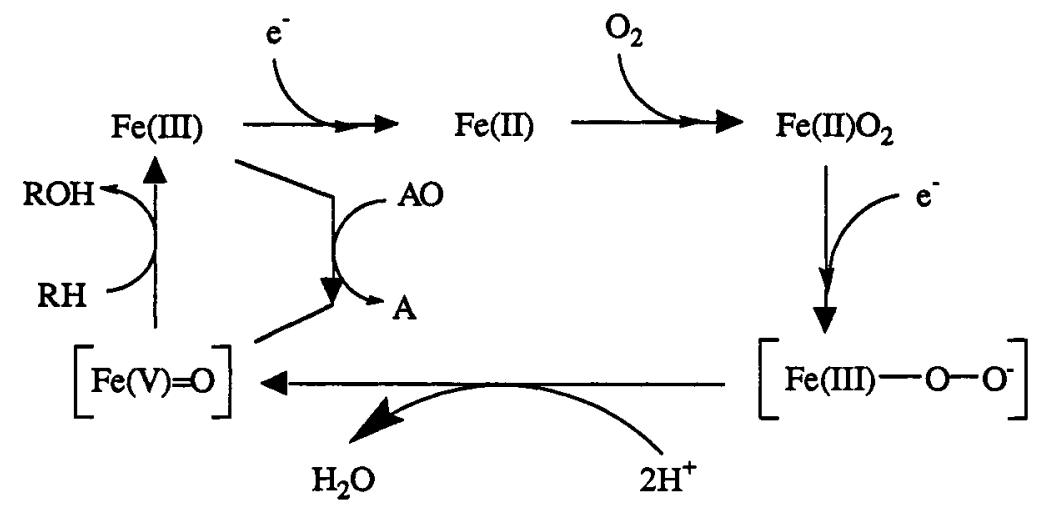

Fig.1 : Simplified view of the long $\left(\mathrm{O}_{2}+2 \mathrm{e}^{-}\right)$and short $(\mathrm{AO})$ catalytic cycles of P450-dependent monooxygenases. $\mathrm{AO}=$ oxygen atom donor.

\section{METALLOPORPHYRIN SYSTEMS MIMICKING CYTOCHROME P450-DEPENDENT MONOOXYGENASES.}

Several recent review articles have been devoted to the huge effort of research made by many groups during these last 13 years to develop efficient model systems based on metalloporphyrin catalysts in order to mimic either the long catalytic cycle or the shortened catalytic cycle of cytochrome P450-dependent monooxygenases (3-9). Most often, these systems associate an Fe(III) or Mn(III) meso-tetraaryl porphyrin with either an oxygen atom donor like $\mathrm{PhIO}, \mathrm{ClO}^{-}, \mathrm{H}_{2} \mathrm{O}_{2}$ or $\mathrm{RCO}_{3} \mathrm{H}$, or $\mathrm{O}_{2}$ and a reducing agent. Such systems were found able to generate high-valent metal-oxo intermediates of the $\mathrm{Fe}(\mathrm{V})=\mathrm{O}$ or $\mathrm{Mn}(\mathrm{V})=\mathrm{O}$ type, and to reproduce most reactions of cytochrome P450-dependent monooxygenases, at least from a qualitative point of view. The main problem encountered with these systems was an oxidative degradation of the metalloporphyrin during catalysis. A first major improvement of these catalysts was obtained by introducing electron-withdrawing substituents on the four meso-aryl rings. More recently, even better and more robust catalysts were obtained by introducing electron withdrawing substituents not only on the meso-aryl rings but also at the $\beta$-pyrrole positions of the porphyrin. The following examples illustrate the particularly high efficiency of these third generation iron porphyrins.

The two $\beta$-octahalogenoporphyrins $\mathrm{Fe}$ (III)(TDCPBr8 8 ) Cl and $\mathrm{Fe}(\mathrm{III})\left(\mathrm{TDCPCl}_{8} \mathrm{P}\right) \mathrm{Cl}$ (Fig.2) were found as much better catalysts than the corresponding second generation iron porphyrin having only $\beta$-hydrogens, $\mathrm{Fe}(\mathrm{TDCPP}) \mathrm{Cl}$, for the hydroxylation of linear alkanes like heptane or pentane by PhIO (10). Thus, heptane was hydroxylated with yields up to $80 \%$ within less than $1 \mathrm{~h}$ at room temperature in the presence of $\mathrm{Fe}\left(\mathrm{TDCPCl}{ }_{8} \mathrm{P}\right) \mathrm{Cl}$ (instead of $36 \%$ with $\mathrm{Fe}(\mathrm{TDCPP}) \mathrm{Cl}$ )(eq.3). 


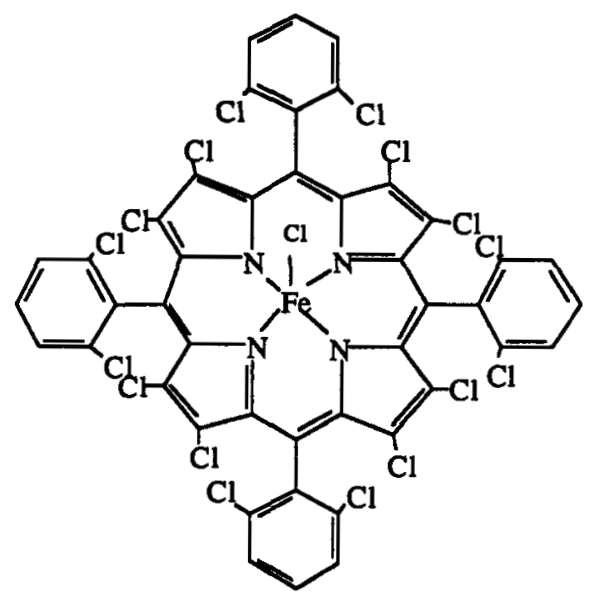

$\mathrm{Fe}\left(\mathrm{TDCPCl}_{8} \mathrm{P}\right) \mathrm{Cl}$

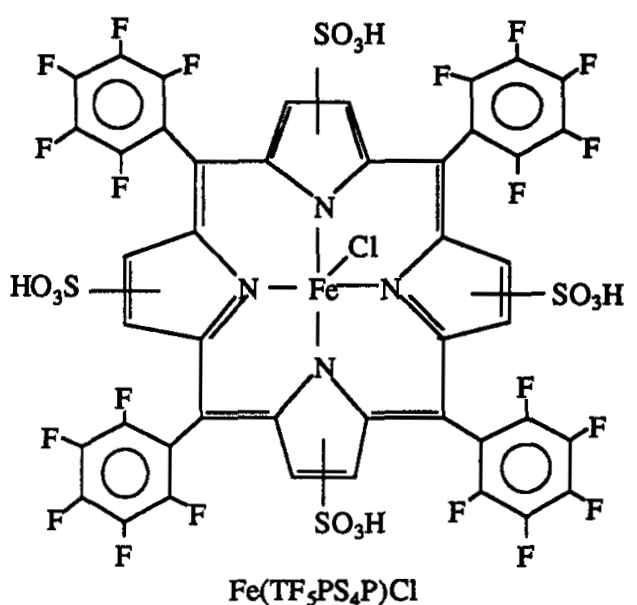

$\mathrm{Fe}\left(\mathrm{TF}_{5} \mathrm{PS}_{4} \mathrm{P}\right) \mathrm{Cl}$

Fig.2 : Formula of some third generation $\beta$-substituted iron-tetraarylporphyrins.

$$
\text { heptane + PhIO } \stackrel{\mathrm{Fe}\left(\mathrm{TDCPCl}_{8} \mathrm{P}\right) \mathrm{Cl}}{\longrightarrow} \text { heptanols + heptanones }(80 \%) \text { (eq.3) }
$$

The water-soluble third generation catalyst $\mathrm{Fe}(\mathrm{III})\left(\mathrm{TF}_{5} \mathrm{PS}_{4} \mathrm{P}\right.$ ) (Fig. 2) gave particularly good results in the oxidation of aromatic rings. Thus, several methoxyarenes bearing electron-donating groups were oxidized to the corresponding quinones by the water soluble oxygen atom donor Mg-mono-peroxyphthalate (MMP), in the presence of this iron porphyrin with yields between 50 and $95 \%$ (eq.4) $(11,12)$. This reaction was successfully applied to the preparation of the natural product methoxatin (or PQQ) by oxidation of a methoxyarene precursor (eq.5) (11).

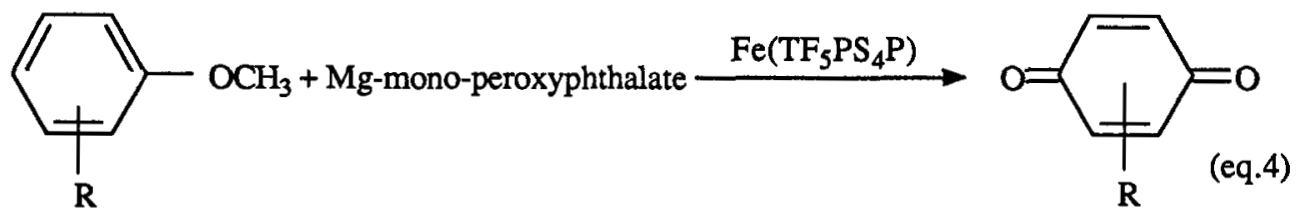

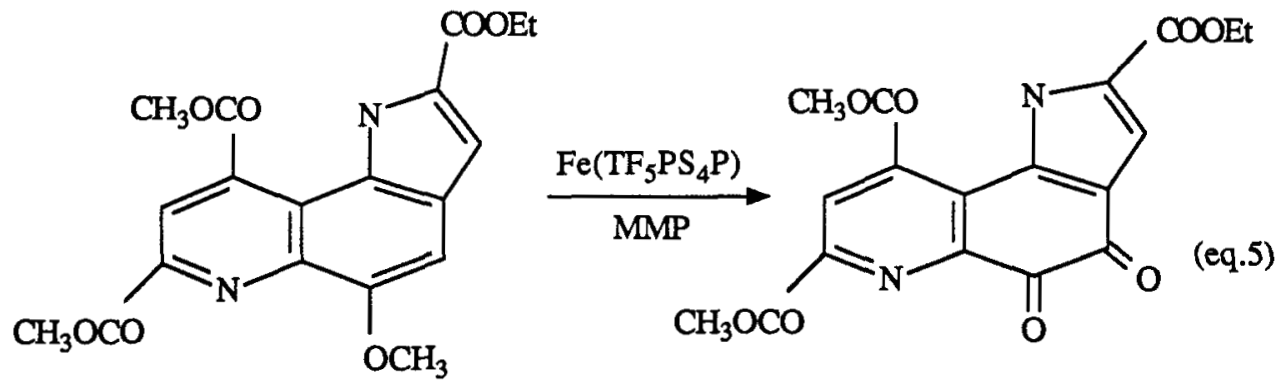

Interestingly enough, oxidation of dimethoxyarenes bearing an electron-withdrawing substituent by this system led to the selective formation of muconic dimethyl esters derived form the cleavage of the ring C-C bond bearing the two methoxy substituents $(12,13)$ (eq.6). This reaction provides a new access to functional muconic diesters with yields around $40 \%$. Interestingly, sulfonated iron porphyrins of the first 
and second generation failed to give any muconic diester under identical conditions. The formation of quinones or muconic diesters from dimethoxyarenes involve several steps - i.e. the insertion of two oxygen atoms coming from $\mathrm{H}_{2} \mathrm{O}$ or the oxidant, the cleavage of a $\mathrm{C}-\mathrm{O}$ or $\mathrm{C}-\mathrm{C}$ bond, and the consumption of two moles of oxidant per mole of transformed substrate. The most likely first step of the reaction is a oneelectron transfer from the dimethoxyarene substrate to the iron-oxo active species (11-13). The high selectivity observed for the formation of quinones or muconic diesters in the presence of Fe (TF5 $\mathrm{PS}_{4} \mathrm{P}_{\text {) }}$ should be due to a very good control of the substrate-derived free radical intermediates by the iron during the whole catalytic cycle (11-13).<smiles>[R]c1ccc(OC)c(OC)c1</smiles>

Such model metalloporphyrin systems reproduce quite well the chemistry performed by the $\mathrm{Fe}(\mathrm{V})=0$ intermediate of the P450 catalytic cycle. In fact, these chemical model systems, as well as some biotechnological systems in which various mammalian cytochromes P450 have been expressed in microorganisms, appear as good tools to study the oxidative metabolism of drugs and other xenobiotics and their pharmacological and toxicological implications $(14,15)$.

\section{OTHER CATALYTIC FUNCTIONS OF CYTOCHROMES P450 RECENTLY DISCOVERED.}

\section{D.1. Cytochromes $\mathrm{P} 450$ as isomerases, dehydrases and reductases}

Quite recently, it has been found that some cytochromes $\mathrm{P} 450$ are able to catalyze reactions very different from oxygen atom transfer. For instance, prostacycline and thromboxane synthases are cytochromes P450 acting simply as isomerases (16) (eq.7), and a plant cytochrome P450 catalyzes the dehydration of a fatty acid hydroperoxide with formation of an allene oxide (17) (eq.8). The corresponding cytochromes P450 do not consume $\mathrm{O}_{2}$ and NADPH, and are not linked to electron-transfer proteins. Their catalytically active species is not the oxoferryl intermediate, but simply the resting Fe(III) state of these cytochromes, which is able to cleave the $\mathrm{O}-\mathrm{O}$ bond of their peroxidic substrates in order to start the isomerisation or dehydration process.
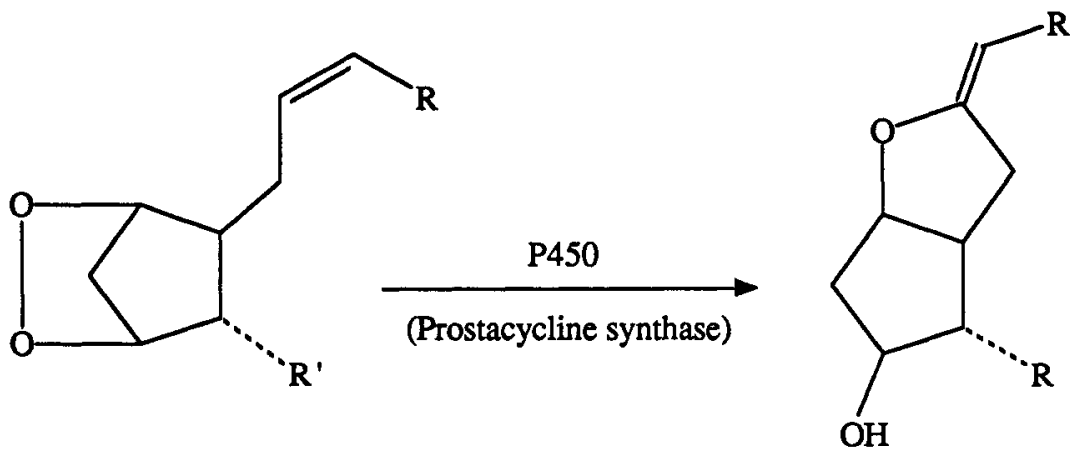

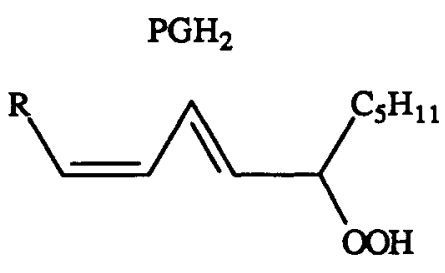

13-HPOD

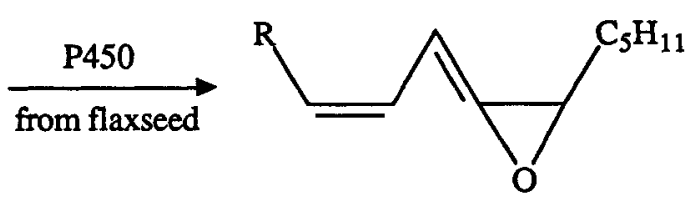

(eq.8)

allene oxide 
Mammalian cytochromes $\mathrm{P} 450$ have been found for many years to act as reductases, since they catalyze the reduction of halogenated compounds, nitroaromatics and arene oxides. More recently, a cytochrome P450 was found responsible for the reduction of $\mathrm{NO}_{2}{ }^{-}$into $\mathrm{N}_{2} \mathrm{O}$ and for energy production in an anaerobic microorganism grown on $\mathrm{NO}_{2}{ }^{-}$as energy source (18) (eq.9).

$$
\mathrm{NO}_{2}^{-}+\mathrm{NADH} \underset{\text { Fusarium oxysporum }}{\stackrel{\mathrm{P} 450}{\longrightarrow}} \mathrm{N}_{2} \mathrm{O}
$$

These cytochrome P450-dependent reductions are performed by the Fe(II) state of the hemeprotein, the electrons being transfered from NADPH (or NADH) to substrates via electron transfer proteins and are often inhibited by $\mathrm{O}_{2}$.

\section{D.2. Cytochromes $\mathrm{P} 450$ as aldoxime dehydrases.}

Another intriguing, recently discovered, reaction of cytochromes P450 is the dehydration of aldoximes to nitriles (eq.10) (19). This reaction does not need any consumption of $\mathrm{O}_{2}$ and NADPH as expected for a simple dehydration reaction. However, contrary to the dehydration catalyzed by allene oxide synthase (eq.8) which is performed by $\mathrm{P} 450 \mathrm{Fe}$ (III), this dehydration is catalyzed by the $\mathrm{Fe}$ (II) state of cytochrome P450. Mechanistic studies have shown that there is a direct relationship between the formation of a cytochrome P450 Fe(II) complex with aldoximes and their dehydration to nitriles (J.L. Boucher, M. Delaforge, D. Mansuy, in preparation).

$$
\mathrm{RCH}=\mathrm{N}-\mathrm{OH} \stackrel{\mathrm{P} 450 \mathrm{Fe}(\mathrm{II})}{\longrightarrow} \mathrm{RC} \equiv \mathrm{N}+\mathrm{H}_{2} \mathrm{O}
$$

Some Z-aldoximes, but not E-aldoximes, are good ligands of rat liver P450 $\mathrm{Fe}$ (II) and lead to P450 complexes characterized by a Soret peak at $443 \mathrm{~nm}$. Moreover, only these Z-aldoximes are dehydrated to the corresponding nitriles in the presence of $\mathrm{P} 450 \mathrm{Fe}$ (II). Therefore, it is likely that this dehydration begins by an electron transfer between $\mathrm{P} 450 \mathrm{Fe}$ (II) and the $\mathrm{C}=\mathrm{NOH}$ bond of the aldoxime (eq.11).

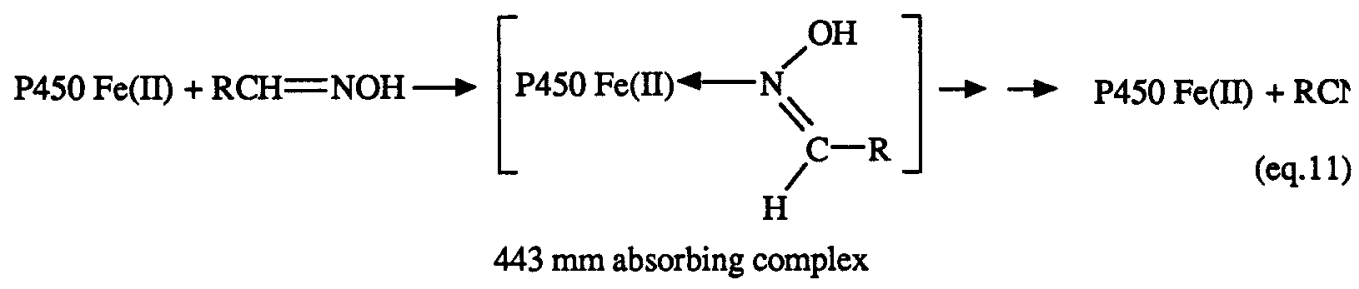

\section{D.3. Cytochromes P450 and Nitric Oxide Synthases.}

Nitric Oxide, NO, has been recognized as an important mediator in the cardiovascular system, in brain and in the immune system (20). In the body, NO is produced by an oxidation of arginine catalyzed by NO synthases. This reaction is performed in two steps : (i) the N-hydroxylation of the terminal guanidine nitrogen of arginine with consumption of $\mathrm{NADPH}$ and $\mathrm{O}_{2}$, and (ii) the oxidative cleavage of the $\mathrm{C}=\mathrm{N}$ bond of $\mathrm{N}$-hydroxy-arginine with consumption of one mol of $\mathrm{O}_{2}$ and $0.5 \mathrm{~mol}$ of NADPH (eq.12 and 13).

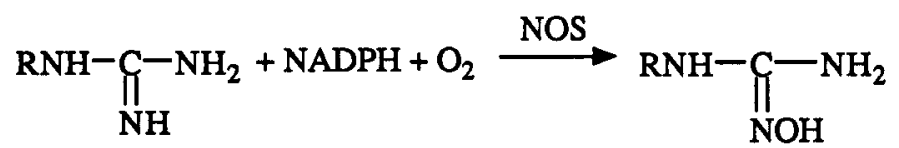

arginine

N-hydroxyarginine (NOHA)

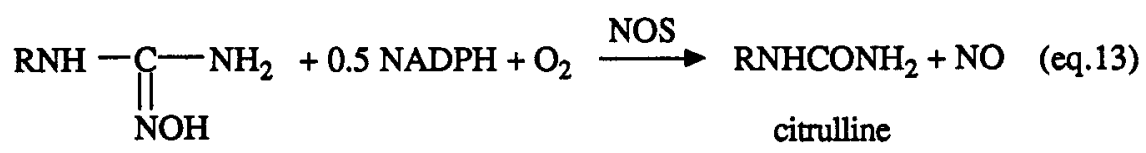


We have recently shown that the second step of NOS, the oxidation of NOHA to citrulline and NO, is also performed by liver cytochromes P450 (21), the most active isozymes being the P450s of the 3A subfamily (22) (eq.14). As cytochromes P450 were found to catalyze the $\mathrm{N}$-hydroxylation of amines or amidines (23), these results suggested that the two steps of NO formation catalyzed by NOS could exhibit a P450like mechanism (21).

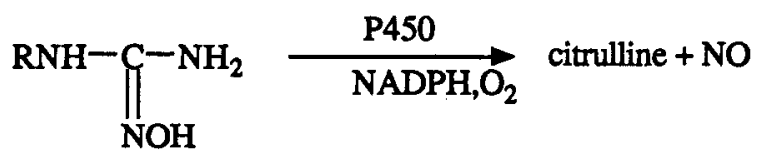

Accordingly, NO synthases were found as heme-thiolate proteins characterized, as cytochromes $\mathrm{P} 450$, by a Soret peak at $450 \mathrm{~nm}$ for their iron(II)-CO complex (24-27). However, although the polypeptide chain of NO synthases contains a sequence exhibiting a high homology with the sequence of cytochrome P450 reductase (29), no clear sequence homology was found between cytochromes P450 and NOSs (27). In fact, if one considers the aminoacid segments of NO synthases containing a cysteine, one finds a nonapeptide highly conserved in all NOSs sequenced so far which is very similar to the decapeptide segment responsible for heme binding in cytochromes P450 (22) (Fig.3).

\begin{tabular}{|c|c|c|c|c|c|c|c|c|c|c|}
\hline $\begin{array}{l}\text { Role in heme } \\
\text { binding }\end{array}$ & $\begin{array}{l}\text { cysteinate } \\
\text { protection }\end{array}$ & & & $\begin{array}{l}\text { hairpin } \\
\text { turn } \\
\text { initiation }\end{array}$ & & $\begin{array}{l}\text { interaction } \\
\text { with heme } \\
\text { propionate }\end{array}$ & & $\begin{array}{l}\text { proximal } \\
\text { cysteinate }\end{array}$ & & $\begin{array}{l}\text { close } \\
\text { contact to } \\
\text { the heme }\end{array}$ \\
\hline P450 cam & $\mathbf{F}$ & $\mathbf{G}$ & $\mathbf{H}$ & G & $S$ & H & L & $\mathrm{C}_{357}$ & $\mathbf{L}$ & $\mathbf{G}$ \\
\hline P450 (consensus) & $\mathbf{F}$ & $G / S$ & $\mathbf{x}$ & $\mathbf{G}$ & $\mathbf{x}$ & $\mathbf{R}$ & $\mathbf{x}$ & $\mathbf{C}$ & hy & $\mathbf{G}$ \\
\hline \multirow[t]{2}{*}{ P450 3A1 } & $\mathbf{F}$ & $\mathbf{G}$ & $\mathbf{N}$ & $\mathbf{G}$ & $\mathbf{P}$ & $\mathbf{R}$ & $\mathbf{N}$ & $\mathrm{C}_{443}$ & I & $\mathbf{G}$ \\
\hline & - & & : & - & : & : & & : & : & : \\
\hline $\mathrm{mm}$ NOS & $\mathbf{W}$ & $\mathbf{R}$ & $\mathbf{N}$ & $\mathbf{A}$ & $\mathbf{P}$ & $\mathbf{R}$ & - & $\mathrm{C}_{194}$ & I & $\mathbf{G}$ \\
\hline rb NOS & $\mathbf{W}$ & $\mathbf{R}$ & $\mathbf{N}$ & A & $\mathbf{S}$ & $\mathbf{R}$ & - & $C_{415}$ & $\mathbf{v}$ & $\mathbf{G}$ \\
\hline
\end{tabular}

Fig.3 : Comparison of the 10-aminoacid sequence responsible for heme binding in P450s with a highly-conserved cysteine-containing peptide in NO synthases (from ref.22). $\mathrm{P} 450_{\text {cam }}$ is for $\mathrm{P} 450$ from Pseudomonas putida grown on camphor ; $\mathrm{mm}$ NOS and $\mathrm{rb}$ NOS for mouse macrophage and rat brain NO synthases. The segment called P450 (consensus) is drawn from the compilation of a great number of P450 sequences (22). The one-letter code for aminoacids is used ; aminoacid positions with low consensus are indicated by $\mathbf{x}$; hy means a hydrophobic aliphatic aminoacid $(\mathrm{L}$, $\mathrm{I}, \mathrm{V}$ or $\mathrm{A}$ ). For the alignment between P450 3A1 and macrophage NOS, sequence identity is denoted by ":" and conservative aminoacid substitution by".". References for the various indicated sequences are indicated in ref. 22.

This segment contains the four aminoacids which have functional roles in the binding of the heme : (i) the cysteine acting as a proximal iron ligand, (ii) the glycine which is in close contact to the heme, (iii) the arginine (or histidine in some $\mathrm{P} 450 \mathrm{~s}$ ) which interacts with a heme propionate, and, (iii) the aromatic aminoacid responsible for the protection of the proximal cysteinate (a phenylalanine in P450s and a tryptophan in NOs). The main difference between the putative heme-binding peptides in NOSs and in P450s is the absence of one aminoacid between the arginine and the cysteine in NOSs. Molecular graphic modeling experiments (Insight II and Discover programs from Biosym Biotechnologies), however, suggest that this one-aminoacid deletion still allows the key interactions between the heme and the proximal region (J.P. Renaud and D. Mansuy, to be published). Briefly, starting from the crystallographic structure of 
P450cam, the 10 aminoacids of the proximal segment (FGHGSHLCLG) were replaced by the 9 corresponding aminoacids of NOSs (WRNAPRCIG), keeping constant the position of the cysteinate and of the following glycine and superimposing the aryl group of the $\mathrm{N}$-terminal tryptophan to that of the corresponding phenylalanine of P450cam, and then subjecting the new structure to energy minimization. Interestingly, in this model, the arginine at position 2 in NOSs was found suitably located to create a salt bridge with the second heme propionate. Naturally, many experiments using for instance site-directed mutagenesis on NOSs remain to be carried out to confirm the importance of this 9-aminoacid segment for heme binding. However, the occurrence of this short sequence in all NOSs described to date and its high analogy with the heme-binding region in P450s make it a good candidate for heme-binding in NOSs.

The great analogy between the heme binding sequences of P450s and NOSs suggests that the NO synthases should exhibit several properties similar to those of the cytochrome P450 superfamily. One could even speculate that NO synthases would be the most sophisticated members of the cytochrome P450 multigene family. As the cytochrome P450 from Bacillus megaterium (28), NOSs contain, in a single polypeptide chain, a FAD- and FMN-containing domain very similar to P450 reductase and a cytochrome P450 domain (Fig.4). In addition, NO synthases contain a sequence responsible for calmodulin binding (30).

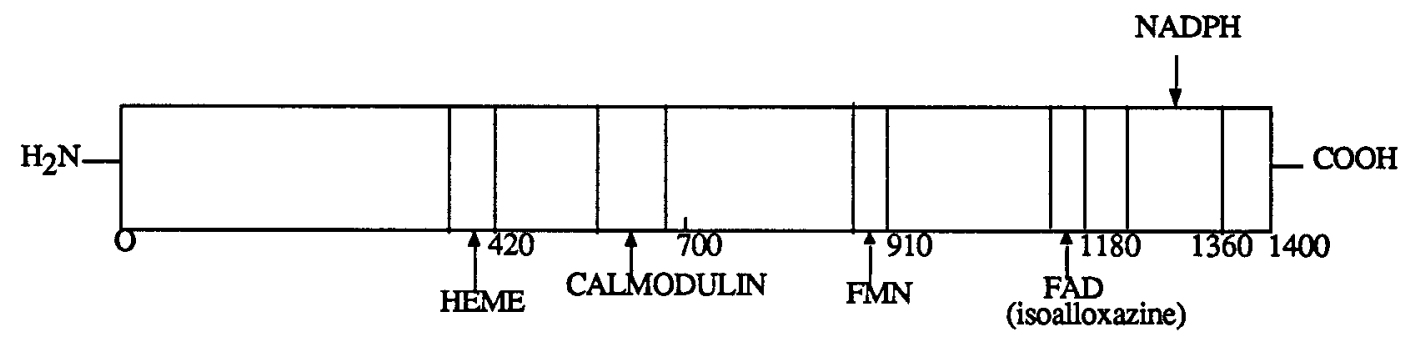

Fig. 4 : Schematic view of the sequence and cofactors of brain NO synthase (the presence of tetrahydrobiopterin is not indicated).

They also require the tetrahydrobiopterin cofactor for optimal activity. The precise role of this cofactor remains to be determined.

\section{E. CONCLUSION}

Cytochromes $\mathrm{P} 450$ appear as surprisingly versatile biocatalysts. Besides their role as monooxygenases which is the most frequently encountered and which was discovered a long time ago, cytochromes P450 were found to catalyze very different reactions like isomerisations, reductions and dehydrations. This surprising diversity of P450 catalyzed reactions is due to the different intrinsic reactivities of the various iron complexes involved in the P450 catalytic cycle. Monooxygenations are performed by the $\mathrm{Fe}(\mathrm{V})=0$ intermediate, and such oxygen atom transfers can also be performed in a highly efficient manner by metalloporphyrin model systems. Some P450-catalyzed isomerisations and dehydrations involves the P450 $\mathrm{Fe}$ (III) state as the active species whereas the P450-catalyzed dehydration of aldoximes is performed by the P450 Fe(II) intermediate. Finally, both NO synthases and cytochromes P450 are heme-thiolate proteins which catalyze the oxidative cleavage of the $\mathrm{C}=\mathrm{NOH}$ bond of $\mathrm{N}^{\omega}$-hydroxyarginine. These two hemeproteins exhibit very similar heme binding sequences, and NO synthases could be highly sophisticated cytochromes P450.

\section{REFERENCES}

1. D. R. Nelson, T. Kamataki, D.J. Waxman, F.P. Guengerich, R.W. Estabrook, R. Feyereisen, F.J. Gonzalez, M.J. Coon, I.C. Gunsalus, O. Gotoh, K. Okuda, and D.W. Nebert, D.N.A. and Cell Biology, 12: 1 (1993).

2. Cytochrome P450. Structure. Mechanism and Biochemistry (P.R. Ortiz de Montellano, ed.), Plenum Press, New-York (1986).

3. D. Mansuy and P. Battioni "Dioxygen activation at heme centers in enzymes and synthetic analogs" in : Bioinorganic Catalysis, (J. Reedjik ed.), M. Dekker, New York, p.422 (1993).

4. D. Mansuy, P. Battioni, and J.P. Battioni, Eur. J. Biochem., 184: 267 (1989). 
5. D. Mansuy, Pure Appl. Chem., 59: 759 (1987).

6. T.J. McMurry and J.T. Groves, Metalloporphyrin models of cytochrome P450, in : Cytochrome P450. Structure Mechanism and Biochemistry, (P.R. Ortiz de Montellano, Ed.), Plenum Press, New-York, p.1 (1986).

7. B. Meunier, Bull. Soc. Chim. Fr, 4: 578 (1986).

8. T.C. Bruice, Ann. N.Y. Acad. Sci. 471: 83 (1986).

9. B. Meunier, Chem. Rev, 92: 1411 (1992).

10. J.F. Bartoli, O. Brigaud, P. Battioni and D. Mansuy, J. Chem. Soc. Chem. Commun. 440 (1991).

11. I. Artaud, K. Ben Aziza, C. Chopard and D. Mansuy, I. Chem. Soc. Chem. Commun., 31 (1991).

12. I. Artaud, K. Ben Aziza and D. Mansuy, L. Org. Chem. in press (1993).

13. I. Artaud, H. Grennberg and D. Mansuy, L. Chem. Soc. Chem. Commun, 1036 (1992).

14. M.N. Carrier, P. Battioni, and D. Mansuy, Bull. Soc. Chim. Fr., in press (1993).

15. D. Mansuy, Pure Appl. Chem, 62: 741 (1990).

16. M. Haurand and V. Ullrich, I. Biol, Chem., 260: 15059 (1985).

17. W.C. Song and A. R. Brash, Science, 253: 781 (1991).

18. H. Shoun and T. Tanimoto, L. Biol. Chem. 266: 11078 (1991).

19. E.G. De Master, F.N. Shirota and H.T. Nagasawa, L.Org.Chem., $57: 5074$ (1992).

20. S. Moncada, R.M.J. Palmer, E.A. Higgs, Pharmacol. Rev. 43: 109-142 (1991).

21. J.L. Boucher, A. Genet, S. Vadon, M. Delaforge, Y. Henry, and D. Mansuy, Biochem. Biophys. Res. Commun, 187: 880 (1992).

22. J.P. Renaud, J.L. Boucher, S. Vadon, M. Delaforge and D. Mansuy, Biochem. Biophys. Res. Comm., 192: 53-60 (1993).

23. B. Clement, M. Immel, H. Pfunder, S. Schmitt, M. Zimmerman in N-oxidation of Drugs, (P. Hlavica and L.A. Damani Ed.) pp 185-204, Chapman and Hall, London (1991).

24. K.A. White and M.A. Marletta, Biochemistry, 31: 6627 (1992).

25. D.J. Stuehr and M.I. Saito, J, Biol. Chem., 267: 20547 (1992).

26. P. Klatt, K. Schmidt, and B. Mayer, Biochem. J., 288: 15 (1992).

27. K. McMillan, D.S. Bredt, D.J. Hirsh, S.H. Snyder, J.E. Clark, and B.S.S. Masters, Proc, Natl. Acad. Sci. USA, 89: 11141 (1992).

28. R.T. Ruettinger, L.-P. Wen, and A.J. Fulco, L. Biol Chem, 264: 10987 (1987).

29. D.S. Bredt, P.M. Hwang, C.E. Glatt, C. Lowenstein, R.R. Raed, and S.H. Snyder, Nature, 351: 714 (1991).

(30) D.S. Stuehr, and O.W. Griffith, Adv. Enzymol. 65: 287 (1992). 